\title{
PROCESSING OF THE RESULTS OF SATELLITE INLAND POSITIONING TRANSPORT USING MOBILE DEVICES AND THEIR VISUALIZATION
}

\author{
Małgorzata Kulas \\ Gdynia Maritime University, Gdynia, Poland \\ *E-mail of corresponding author: malgorzatakulas98@wp.pl
}

\begin{abstract}
Resume
The issue of spatial data visualization is currently an important element in the positioning and navigation process. The constant trend in increasing the accuracy and availability of position modules affects the widespread use of the mobile devices in transport. The paper presents creation of a three-dimensional visualization model based on ground tracks recorded in NMEA (National Marine Electronics Association) and GPX (GPS Exchange Format) formats. Additionally, the study presents an analysis of the positioning accuracy including the sky obstructions presence and the instantaneous state of the satellite constellation. The significant deterioration in positioning accuracies was noted due to the presence of sky obstructions and low movement speed during data recording. The analysis of these parameters showed the dependence of the positioning accuracy with the number of visible satellites and the HDOP (Horizontal Dilution of Precision) parameter.
\end{abstract}

Available online: https://doi.org/10.26552/com.C.2022.1.E36-E48

\section{Article info}

Received 4 May 2021

Accepted 2 August 2021

Online 22 November 2021

\section{Keywords:}

land transport, satellite positioning, NMEA,

GPX,

KML,

visualization

ISSN 1335-4205 (print version)

ISSN 2585-7878 (online version)

\section{Introduction}

Satellite positioning is widely used in both maritime and land transport. The practical application of astronavigation in marine navigation has been almost eliminated by the global satellite navigation systems [1] The issue of visualization of routes in the sea conditions is carried out through the use of the ECDIS (Electronic Chart Display and Information System) system [2]. Based on the readings of the GNSS (Global Navigation Satellite System) sensors, the current position of the ship is determined and then it is related to the electronic map [3]. Concerning the land transport, the issue of the spatial data visualization is related to connection of positional data with the environment. In the period of rapid development of information and geospatial technologies, on-line numerical maps are widely used [4-5]. Another level of detail is imaging based on photogrammetric imaging [6], LIDAR (Light Detection and Ranging) aerial laser scanning [7] and terrestrial laser scanning [8].

Presentation of the routes of movement of people and means of transport is related to the accuracy of satellite positioning. Positioning errors vary depending on the measurement mode and type of receivers. Authors in [9] focused mainly on the aspect of availability of the smartphone positioning service under different conditions and did not include the accuracy results of the devices. In [10] the research topic was determining the positioning accuracy in the rail transport, however, the professional GNSS receivers and INS (Inertial Navigation System) and MEMS (Micro-Electro Mechanical System) inertial modules were used in the study. In [11] and [12] the methodology was presented, as well as verification of the real data for the accuracy analysis of dynamic and stationary satellite measurements. The cited works confirm the variability of the accuracy results in relation to the constant values presented in the official standards issued by the managers of navigation systems, e.g. GPS (Global Positioning System) [13]. The presence of the sky obstacles, which block the reception of satellite signals, is of particular importance from the point of view of positioning accuracy [14]. To increase the accuracy of the determined coordinates, supporting systems are used, e.g. active geodetic networks [15]. In [16] the accuracy of static and dynamic positioning of smartphones was examined in relation to the reference station of an active geodetic network. Similar studies were carried out in [17].

Presentation of the spatial data in numerical form is realized in the form of topography and land cover models. In the second case, especially in highly urbanized cities, different levels of details (LoD) are used [18]. The source of this data is photogrammetric images collected, among others by aerial [19] and surface drone vehicles [20]. The spatial data, after appropriate harmonization [21], are presented in the form of a three-dimensional model with various levels of detail, e.g. the Google Earth [4]. An additional advantage of the above solutions is the 
ability to import external spatial data and display them together with the terrain model. This is an important tool for representing the location of different modes of transport.

The fusion of positioning technology with supporting systems has significantly changed the implementation of the land transport. These solutions are primarily used in personal navigation systems and vehicle fleet monitoring [22]. Vehicle tracking information provides useful data, such as congestion, determining the site of an accident, locating emergency vehicles and the public transport. The above operations significantly support the procedures for traffic management, tracking and managing the fleet of vehicles [23]. An interesting issue concerning the public transport is described in [24] by application of the GNSS and WiFi technologies in determining the position in underground/ subway public transportation conditions, whereas in [25] the methodology of using smartphones for indoor/outdoor navigation in the public transport was presented. The authors did not include the precision parameters for positioning of devices in the study. The application of the satellite positioning also has a key role in the rapidly growing industry of Intelligent Transport Systems (ITS) and autonomous vehicles [26]. In addition, location data is used to coordinate the fleet, determine transport routes, conduct and optimize the transport control [27].

This study is related to presentation of the process of integration of the spatial data from external sources with the spatial model of the Google Earth application. For this purpose, satellite measurements were carried out with use of the four different mobile devices at four locations in Poland and Sweden. The study also involved processing the recorded spatial source data of GNSS receivers into an import format used in the Google Earth application. Moreover, based on the recorded data, a basic positioning accuracy analysis of the used mobile devices was carried out. The study was divided into three main sections describing used data formats, data processing procedures and visualization results.

\section{Materials and methods}

The study used three formats commonly used in the GIS (Geographic Information System) environment: NMEA, GPX, and KML (Keyhole Markup Language). The advantage of the formats is recording of the latitude and longitude coordinates as well as the height relative to the adopted reference level. The name of the first format comes from the NMEA, the creator of standards for digital data exchange between the marine electrical devices [28]. The NMEA standards are open, but access to the full specification is limited and paid for. Currently, there are two versions of the standard: NMEA 0183 and NMEA 2000. Due to the emergence of more and more modern devices, the NMEA standards are constantly being improved, as well.
The NMEA 0183 standard enables one-way data exchange and defines requirements for data protocols, electrical signals, transmission time and sentence format. Devices using the NMEA 0183 use an asynchronous serial interface with strictly defined transmission parameters: speed 4800 bits per second with 8 data bits, one stop bit and no parity [29]. Data is transmitted in sentences with a defined structure and ASCII encoding is used for recording. In the NMEA 0183 transport and navigation applications, a Global Positioning System Fix Data (GGA) message is often used to provide the positioning information [30]. The NMEA 2000 differs from the previous version because it is multi-tasking and self-configuring. The format uses the binary encoding and offers the faster data transmission than the alphanumeric NMEA 0183. It also enables bi-directional data exchange between multiple transmitters and receivers. The NMEA 2000 messages are transmitted as a series of data frames. The standard is primarily used for transmission of the short data messages [28].

The other two formats: GPX and KML are open standards developed based on XML (Extensible Markup Language). The XML defines a set of rules for encoding ASCII documents in such a way that they are both human and machine-readable [31]. Created in 2002, the GPX format defines a set of tags to describe the GNSS survey data and geographic data and allows to indicate user-defined features and attributes. The format allows saving position data in the form of points, routes and tracks. The GPX is supported by many applications and websites and it is considered by many to be the standard format for exchange of the GPS data between the fixed and mobile devices, GNSS receivers and internet services [32].

The second XML-based format is KML (Keyhole Markup Language). According to the documentation of the format, it is used to store the spatial data, with help of which visualizations are created in mobile applications, internet maps, or browsers of three-dimensional Earth models, such as Google Earth [33]. The KML files, unlike the encrypted KMZ format, can be generated either by using the GIS software user interface or created from scratch using XML in a text editor. The KML's feature set includes placemarks, lines, polygons, 3D models, text annotations, images, icons, labels, web links [34]. Each point saved in the KML file is defined by longitude and latitude and optional data defining the view in the $3 \mathrm{D}$ space of the software. The location coding with KML is entered in the form of tuples, i.e. multi-element variables consisting of a sequence of real numbers representing the coordinates in the following order: longitude, latitude and altitude. Horizontal coordinates are defined on the WGS84 ellipsoid (World Geodetic System 1984) [35] and the elevation coordinate is measured with respect to the EGM96 geoid model (Earth Geopotential Model 1996) [36].

Measurements were analyzed after the registration 
was completed and the files were copied to the computer. Processing of the spatial data saved in NMEA and GPX formats is related to the filtering of the content of source files and downloading from them, among others values of geographic coordinates and heights of subsequent points. The visualization of spatial data recorded by mobile devices in this study was carried out in the Google Earth software [6]. Since the Google Earth supports files in KML format, it was necessary to convert the input data to the appropriate form. In the first phase of data processing, the input data, in the form of NMEA messages and GPX file, was transformed into a time series of positional parameters of the measured points. The second phase of processing was to create a text file with a tag structure corresponding to the KML language [37].

Of all the NMEA 0183 messages recorded by mobile devices, the study analyzes used the GGA type containing position data of the receivers. The NMEA 0183 protocol messages are sentences with successive parameters separated by a comma separator. Geographic coordinates in the NMEA GGA format are stored in the form of a series of digits consisting of degrees and minutes. The first coordinate in the message is the latitude, which consists of the first two digits representing the full degree value and the remainder of the floating-point representing the number of arc minutes. The next parameter - the longitude consists of the first three digits that define the number of full degrees [12]. The latitude and longitude coordinates, after separating the whole parts of degrees and minutes, were converted to degrees with a decimal part:

$\varphi=\varphi_{S T}+\frac{\varphi_{M I N}}{60}$

$\lambda=\lambda_{S T}+\frac{\lambda_{M I N}}{60}$

where $\varphi$ is latitude $\left[^{\circ}\right], \varphi_{S T}$ is a number of full degrees of latitude, $\varphi_{\text {MIN }}$ number of angular minutes of latitude, $\lambda$ longitude $\left[^{\circ}\right], \lambda_{S T}$ number of full degrees of longitude, $\lambda_{M I N}$ number of angular minutes of longitude.

The processing of data from the GPX file consisted of extracting the position data based on selected tags. Unlike the NMEA GGA format, the GPX longitude and latitude angular coordinates are given in degrees and do not require additional numeric recalculation. The last stage of data processing from both recording formats is arranging the coordinates of the points in the order required in the KML format, i.e. longitude, latitude and altitude, respectively. The decimal separator in KML format is a period and the separator of values in a given record is a comma. The ordered coordinates of points constituted the body of the KML file. To read it properly in the Google Earth software, it was necessary to add a header and footer defined in the format documentation [37]. The implementation of individual stages of the data processing in the work is presented in Table 1.
It should be noted that the text file used for visualization, containing geospatial data processed from the NMEA and GPX formats, should be saved with the KML extension.

\section{Measurements}

Four mobile devices equipped with the GNSS modules were used to record the satellite data in the study: three smartphones and a smartwatch. The installed GNSS module determines the coordinates, which are then saved on the device's storage medium. In the case of smartphones, obtaining the position data in a file requires installation of a software that reads the signal from the GNSS receiver of the phone and saves it in text files in the NMEA format. The used smartwatch saves the designated coordinates in the GPX format using an appropriate application. The characteristics of the equipment used in the study are presented in Table 2.

The measurement data for visualization by the procedure described in the Materials and Methods section have been registered in Poland (3 routes) and Sweden (1 route). The test route selection criterion reflected the accuracy of the GNSS receivers recorded in the field conditions with varying degrees of satellite signal availability limited by the sky obstacles.

The first measurement on the Stara Kiszewa Gdynia (Poland) route was made while driving a car using a Samsung Galaxy A30S smartphone with an active SIM card. The section is the longest recorded route with a length of $83.7 \mathrm{~km}$. Along the route, there are all variants of presence of the terrain barriers that hinder the accuracy of positioning: difficult, moderate and favorable. The initial part of the route runs through the rural areas characterized by sparse buildings, winding roads, roadside trees and sometimes wooded areas. The middle part of the route is an expressway with no major obstacles. The final part of the recorded route is located in the area of the high urban development in Gdynia.

The second measurement was made with an iPhone 7 smartphone on the route Glava - Arvika (southern Sweden) during the bus ride. The smartphone has an active SIM card. The $29 \mathrm{~km}$ long route runs through agricultural land located between lakes and is characterized by a large forest area. There are no buildings along the entire length of the measurement route. The exceptions are the final route part in the city of Arvika and the village of Sulvik. Most of the measurements were made in difficult conditions with presence of tree obstacles, which significantly reduces the quality of satellite positioning.

The third test section in Gdynia between Gdynia Main Railway Station and seafront was covered on foot. A Huawei Mate 10 Lite mobile phone without an active SIM card was used to record the satellite data. The course of the route was planned in such a way as to ensure the most unfavorable measurement conditions. 
Table 1 Results of the steps for processing the sample NMEA and GPX source data to create a KML export file

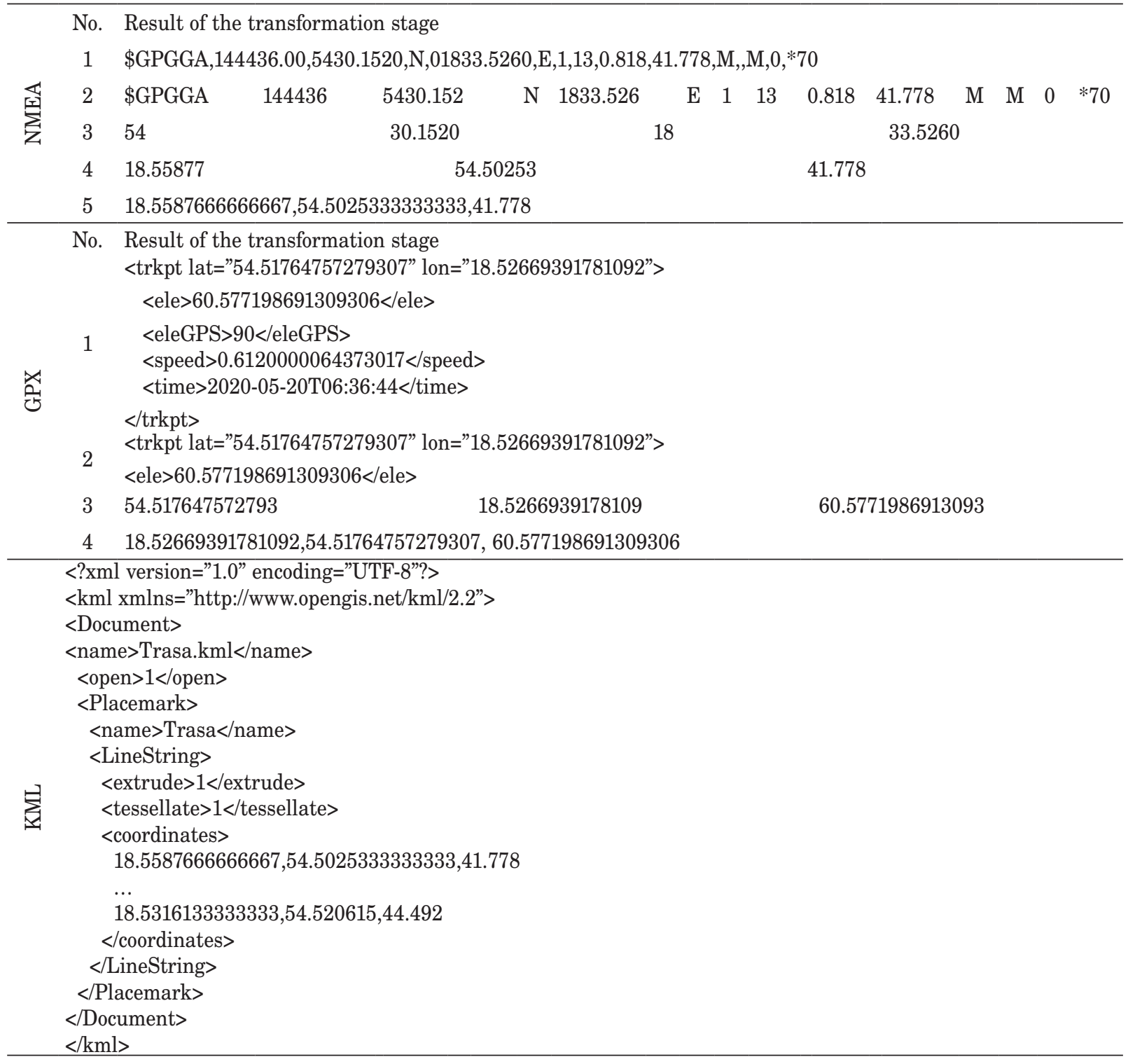

Table 2 Selected technical parameters of the mobile devices used in the study [38-41]

\begin{tabular}{|c|c|c|c|c|}
\hline \multirow[b]{2}{*}{$\begin{array}{l}\text { Measuring } \\
\text { device }\end{array}$} & \multirow[t]{2}{*}{ Samsung Galaxy A30S } & iPhone 7 & \multirow[t]{2}{*}{ Huawei Mate 10 Lite } & \multirow{2}{*}{$\begin{array}{l}\text { Samsung Gear S3 } \\
\text { Frontier }\end{array}$} \\
\hline & & 1.0 & & \\
\hline $\begin{array}{l}\text { Systems } \\
\text { available }\end{array}$ & $\begin{array}{l}\text { GPS, GLONASS, Galileo, } \\
\text { BeiDou }\end{array}$ & GPS & $\begin{array}{l}\text { GPS, GLONASS, } \\
\text { BeiDou }\end{array}$ & $\begin{array}{l}\text { GPS, A-GPS, } \\
\text { GLONASS }\end{array}$ \\
\hline Application & NMEA Tools Pro & NMEA Gps & NMEA Tools Pro & $\begin{array}{l}\text { GPX Tracker, Gear } \\
\text { GPX receiver }\end{array}$ \\
\hline Recording format & NMEA & NMEA & NMEA & GPX \\
\hline Frequency & $1 \mathrm{~Hz}$ & $1 \mathrm{~Hz}$ & $1 \mathrm{~Hz}$ & $1 \mathrm{~Hz}$ \\
\hline $\begin{array}{l}\text { Recorded NMEA } \\
\text { messages }\end{array}$ & $\begin{array}{l}\text { BDGSA, BDGSV, GAGSA, } \\
\text { GAGSV, GLGSV, GNGSA, } \\
\text { GPGGA, GPGSA, GPGSV, } \\
\text { GPRMC, GPVTG }\end{array}$ & $\begin{array}{c}\text { GPGGA, GPGSA, } \\
\text { GPGSV, GPRMC, } \\
\text { GPVTG }\end{array}$ & $\begin{array}{l}\text { BDGSA, BDGSV, } \\
\text { GLGSA, GLGSV, } \\
\text { GNGSA, GPGGA, } \\
\text { GPGSA, GPGSV, } \\
\text { GPRMC, QZGSA }\end{array}$ & not applicable \\
\hline
\end{tabular}


This applies especially to the part of the route running near the vicinity of high urban development. The remainder of the measurement was taken on the seaside boulevard along which the sky is more exposed on the south and south-east sides.

The last test measurement on the Gdynia - Sopot (Poland) route was performed with the Samsung Gear S3 Frontier smartwatch while driving. There are two types of terrain conditions along the route. In the initial section in Gdynia and the final section in the center of Sopot, the sky visibility is limited by buildings. The remaining part of the registered route is a straight course of the road and no buildings near the road. The only terrain obstacles in this section are roadside trees. The list of test routes along with the assessment of field conditions is presented in Table 3 .

The recorded position data represents both different terrain conditions and different speed of movement of the user. Thanks to this, the data is a valuable research material, both in terms of presenting the procedure of transition from the level of saved files with the receiver positions to three-dimensional visualization, as well as for conducting a preliminary assessment of positioning accuracy.

\section{Results}

The NMEA format, in addition to position data, also contains additional information about the instantaneous state of the satellite constellation. The NMEA GGA messages include the following parameters: the number of available satellites and the HDOP factor. Figure 1 shows the parameter values for three routes, where registration was performed on smartphones with the use of NMEA stream recording applications. The graphs show jumps in parameter values in various terrain conditions of the routes traveled.

In the case of the first route Stara Kiszewa - Gdynia (Figure 1a), the number of satellites ranges from 5 to 24 satellites with an average value of 18.6 and for the
Gdynia Centrum route (Figure 1c) it ranged from 13 to 18 with an average value 16.0. For the Glava - Arvika route (Figure $1 \mathrm{~b}$ ) the number of GPS satellites along the entire length of the route was constant and amounted to 12 . The average HDOP value for the Stara Kiszewa Gdynia route was 0.58 , for the Glava - Arvika route 2.54 and for the Gdynia Centrum route 0.72 .

Based on the presented measurement data, it is noticeable that with the greater number of GNSS systems used, the number of visible satellites increases and the HDOP factor takes the lower values. In places located in wooded areas, under viaducts, or in the vicinity of high-rise buildings, the number of visible satellites decreased and the value of the HDOP increased. In addition, for the one-system (GPS) phone, the iPhone 7 has a significantly higher DOP value than the remaining multi-system smartphones, which represents the advantage of using multiple satellite navigation systems to improve the geometry of the satellite system in the user's sky.

The conducted analyses indicate that the number of available satellites and the value of the HDOP are interdependent. It should be noted, however, that the distribution of satellites in the sky, which determines the values of dilution of precision parameter, is of the key importance for the positioning accuracy. With increase in the number of visible satellites and their favorable distribution in the sky, the HDOP decreases and the accuracy of determining the horizontal position increases [43].

An important factor influencing the quality of the measurement is also the speed of the GNSS receiver during the measurement. Therefore, graphs were made to show the speed achieved during the measurement for each of the recorded routes. For this purpose, the \$GPRMC sentences from the NMEA files were used, which contained information about the speed given in knots. The values recorded in $\mathrm{kn}$ were converted to $\mathrm{km} / \mathrm{h}$. For the route saved using the GPX format, the speed was read from the <speed $>$ tag, which contained the values recorded in the destination unit $\mathrm{km} / \mathrm{h}$, so

Table 3 List of test routes with a map orientation plan [42]

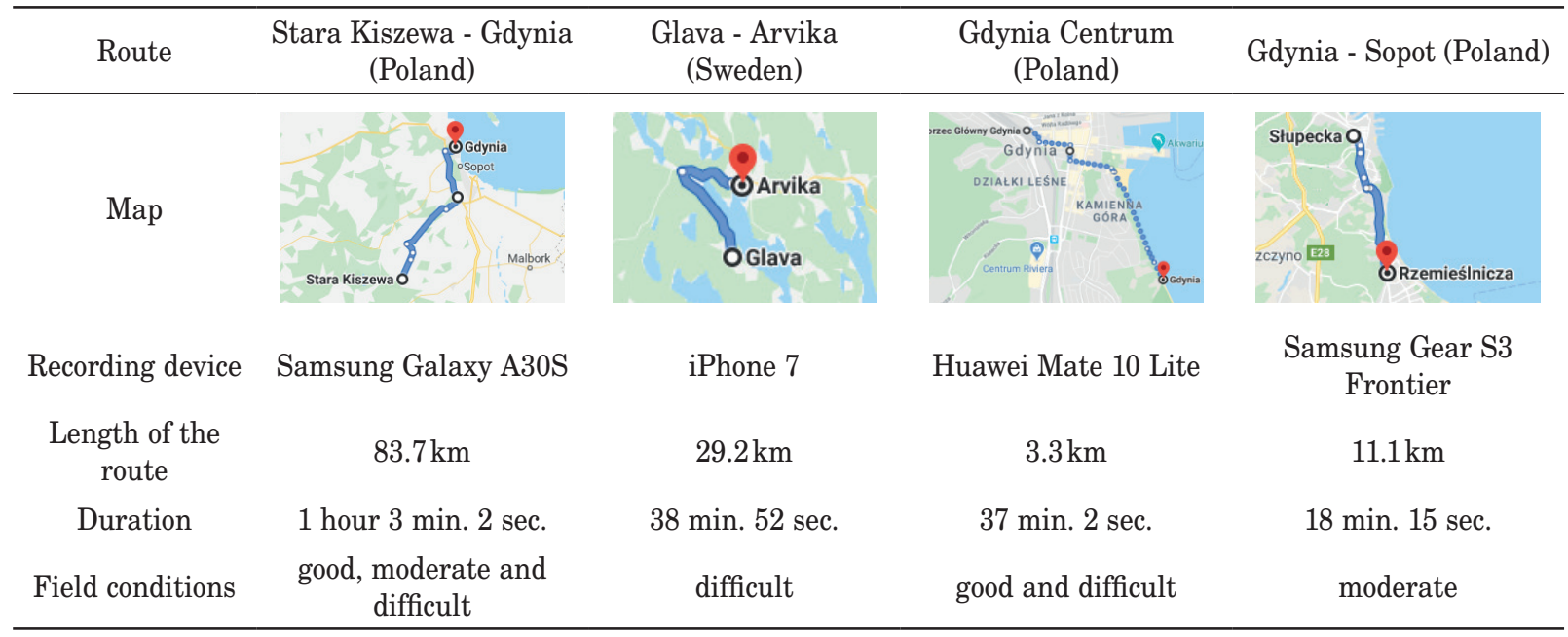


a)

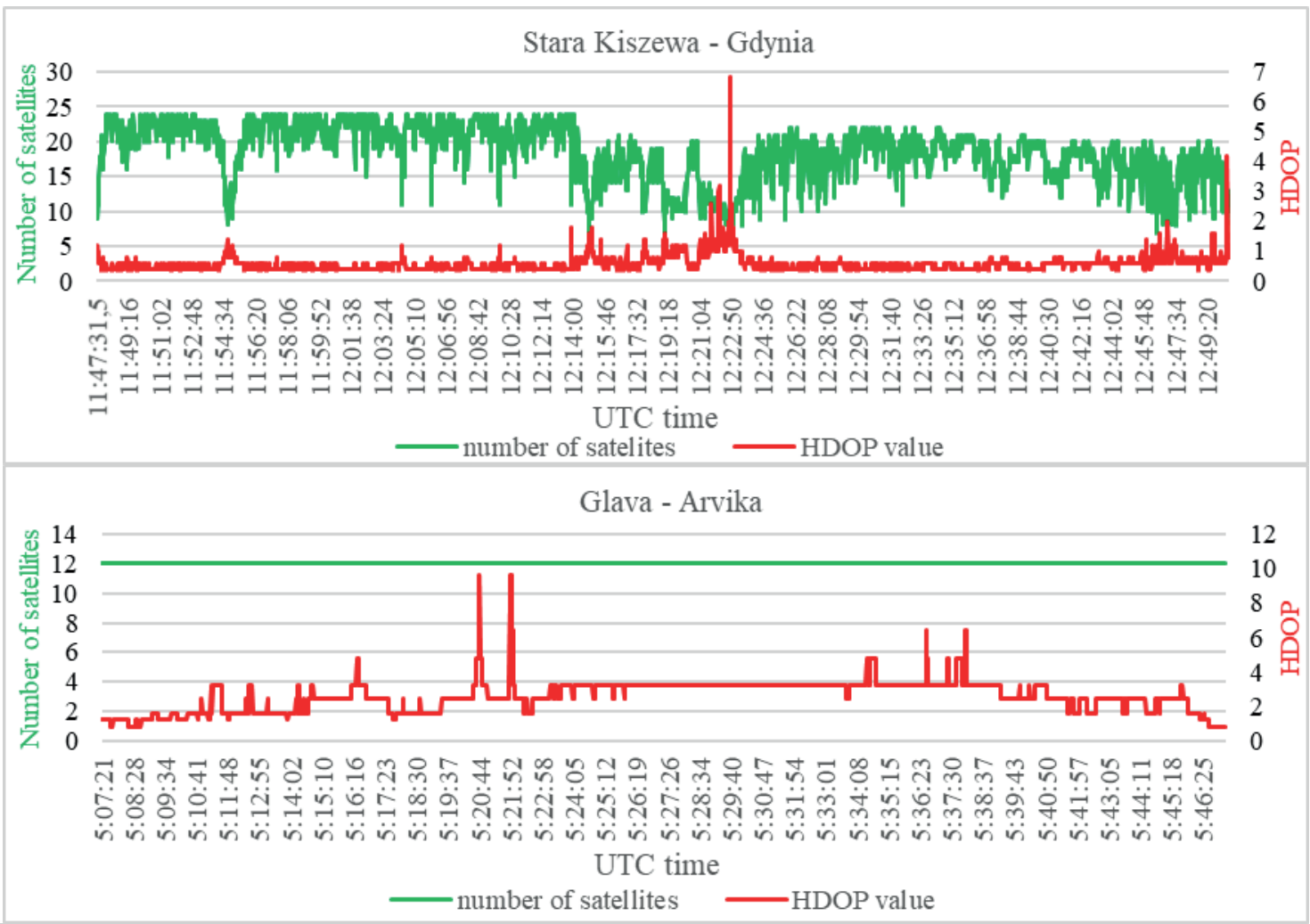

c)

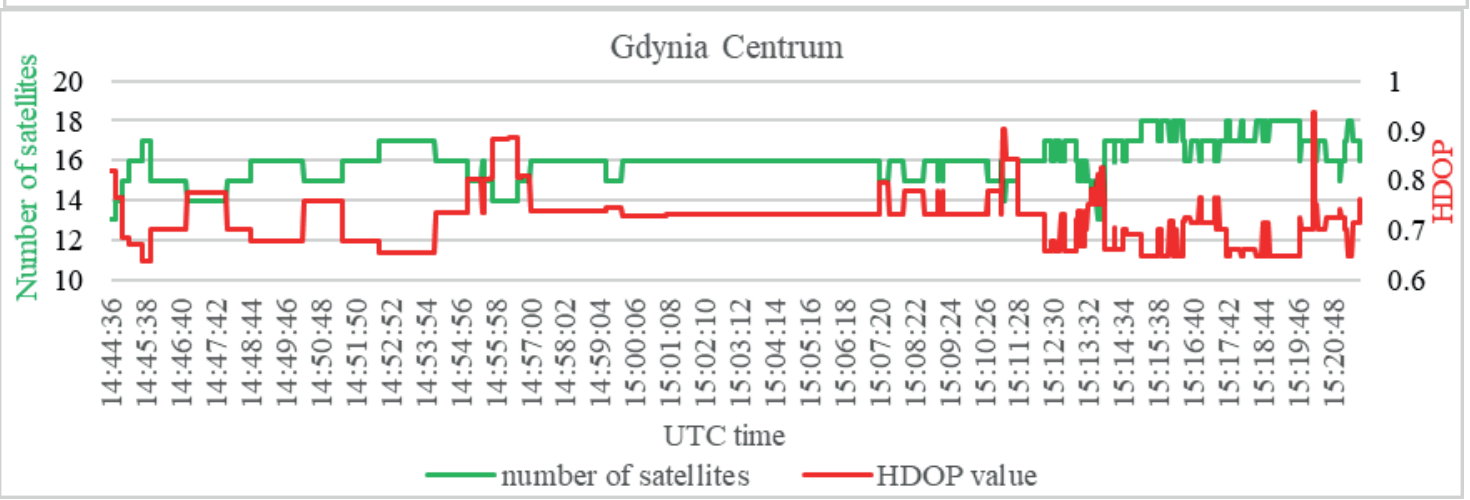

Figure 1 The number of satellites and HDOP from NMEA recording for each route: Stara Kiszewa - Gdynia (a); Glava Arvika (b); Gdynia Centrum (c)

they did not require processing. Figure 2 presents the graphs of the speeds achieved during the registration of individual routes.

It should be noted that the specificity of the mobile devices and applications used do not allow for comparison of all the parameters that could have influenced the size of measurement errors. The applications and algorithms used in the measurement devices allow only the reading and recording of the signal from GNSS receivers in the established NMEA and GPX formats. Information related to the technology implemented in the GNSS receivers of the tested devices is not publicly available. Therefore, parameters such as ionospheric correction, tropospheric correction, correction from the EGNOS system, multipath signals mitigation and the Doppler shift were not included in the data analysis. In addition, information on the Kalman filter software used in the receiver and its settings are unknown and it is only possible to observe the filtering results. The formats used for the data recording also make it impossible to read from the files in how many measuring epochs the position was not determined and with what quality the positions were determined (code / fixed).

In order to assess the size of the measurement errors, the cross-track errors at 100 equally distant route points based on the visualizations were determined in Google Earth. Based on the read values of position errors, graphs were made for each of the routes (Figure 3). In the case of the longest route Stara Kiszewa - Gdynia (Figure 2a) the mean value of the position error was 2.89 with a standard deviation of 3.24. For the route Glava Arvika (Figure 2b) the mean value of the position error was the highest and amounted to 4.04 with a standard deviation of 4.06. For the Gdynia Centrum route (Figure $2 c)$, the mean value of the position error was the lowest and amounted to 1.66 with a standard deviation of 2.50 . 
a)

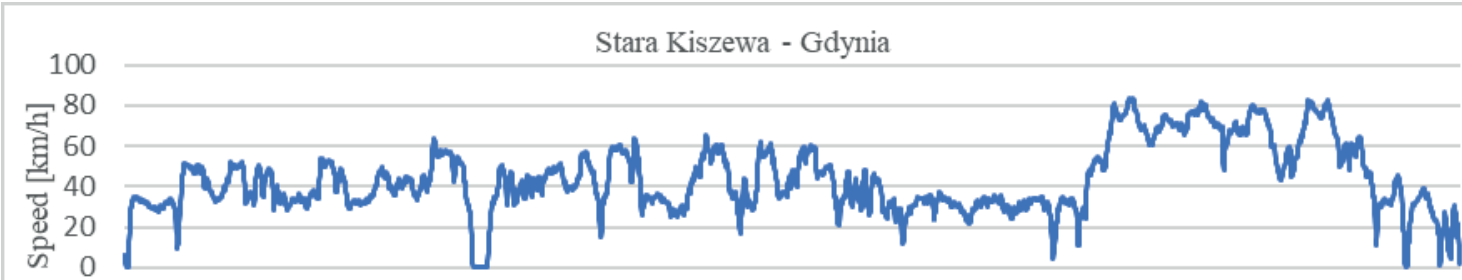

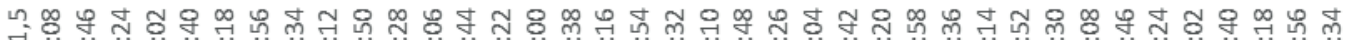

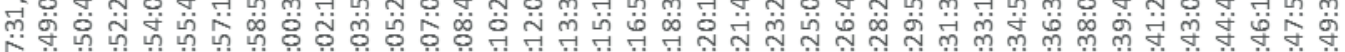

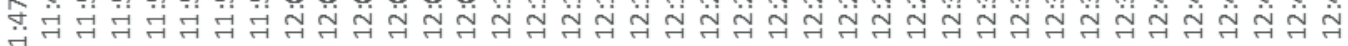

Grime

b)

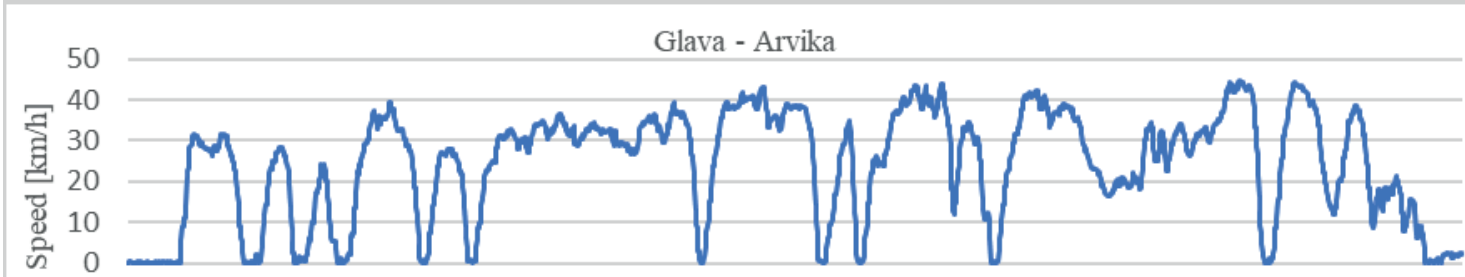

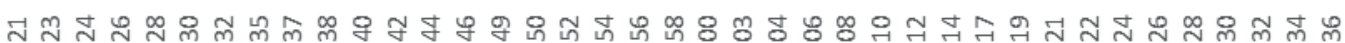

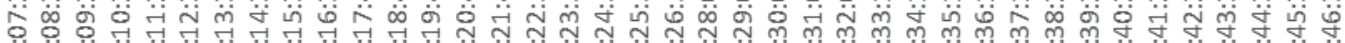

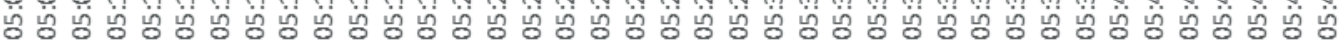
Time

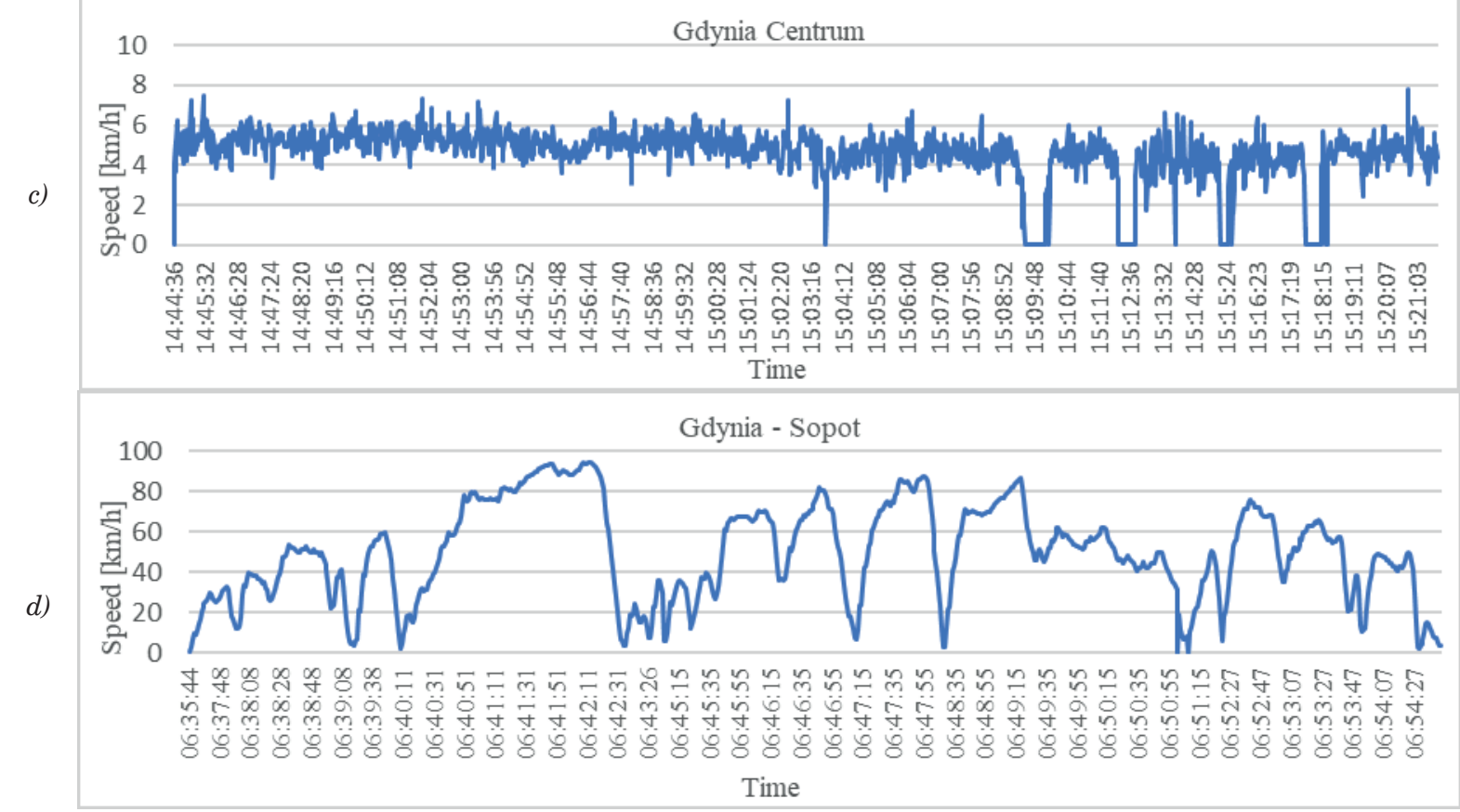

Figure 2 GNSS receivers speed on individual routes: Stara Kiszewa - Gdynia (a); Glava - Arvika (b); Gdynia Centrum (c); Gdynia - Sopot (d)

For the last Gdynia-Sopot route (Figure 2d) the mean value of the position error was 1.71 with the standard deviation 1.77 .

\subsection{Visualization of the route Stara Kiszewa - Gdynia}

In the parts of the rural areas of the Stara Kiszewa - Gdynia route, slight deviations of the recorded track, related to the road, due to the lack of major obstacles are visible. Nevertheless, the presence of single trees near the road or the course of the route through wooded areas causes a noticeable deterioration of accuracy. An example is the section of a winding road leading through the forest in Kolbudy (Figure 4a). Due to the sky obstacles, almost the entire recorded route (yellow) is outside the real position of the road (green). It is a fragment of the measurement representing the UTC range 12:13 12:29 shown in Figure 1a, which is characterized by the highest variation of the HDOP along the entire route, which, at the critical moment, reached the maximum value of 6.8. The number of available satellites has also sharply decreased from 21 to 6 . 
a)
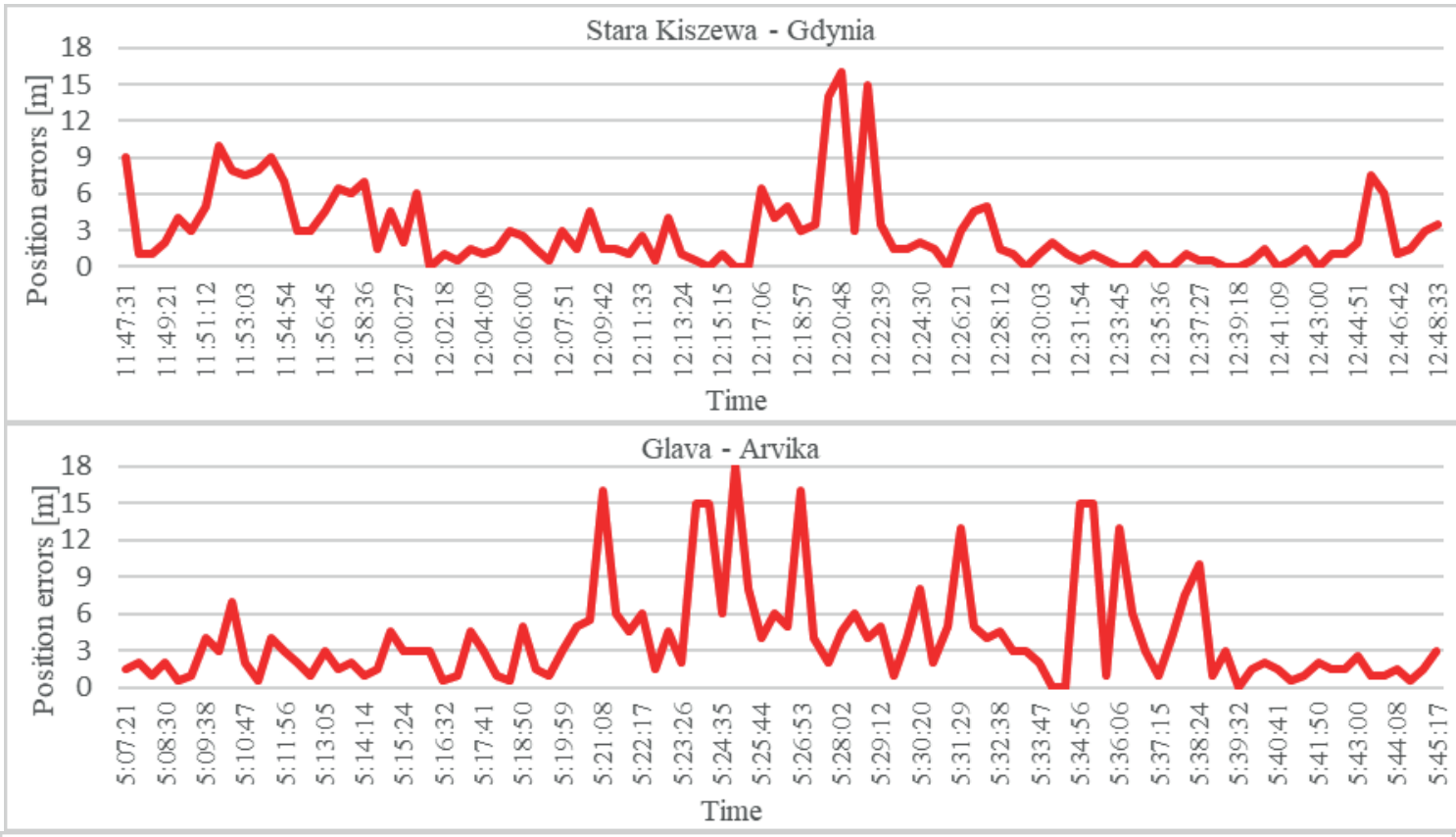

b)

c)
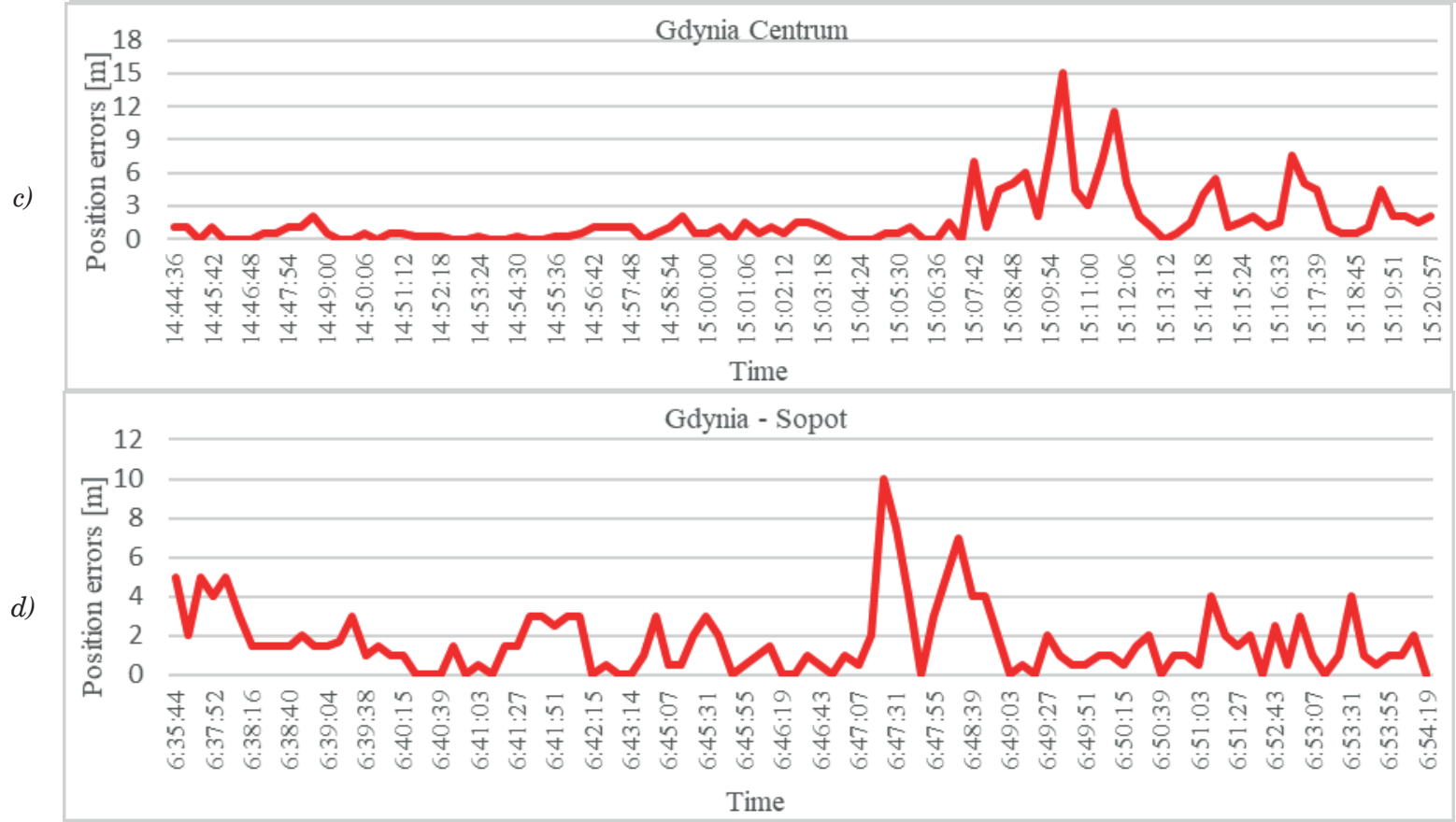

Figure 3 Position errors read on the basis of visualizations made in Google Earth on individual routes: Stara Kiszewa - Gdynia (a); Glava - Arvika (b); Gdynia Centrum (c); Gdynia - Sopot (d)

The section of the route located on the Tricity ring road (Figure $4 \mathrm{~b}$ ) was covered at high speed (Figure 2a, UTC period 12:34 - 12:44), thanks to which no significant disturbances influencing the visualization of the course of the track were recorded. This indicates convenient measurement conditions and high measurement accuracy, close to 1 meter, enabling the identification of the occupied road lane. The course of the curve is influenced by the working Kalman filter [45] smoothing out the outliers of the receiver position. With the predominantly no obstruction of the sky along the expressway, the HDOP values did not exceed 0.8 (Figure 1a).
The projection of the route from the UTC period 12:45 - 12:50 (Figure 1a) located along Morska Street in Gdynia (Figure 4c) has significant and frequent fluctuations in HDOP and the number of satellites due to the high urban development. The HDOP in the presented location was the second largest value of 4.2. In turn, the number of satellites reached the lowest value during the measurement and was 5 . The unfavorable parameters of the satellite constellation in this section did not cause any major fluctuations thanks to use of the Kalman filter. The course of the visualized route is rectilinear, but almost the entire length is outside the real path. 


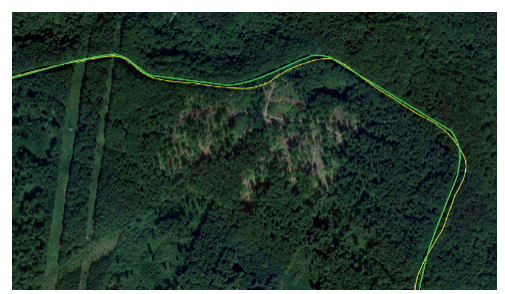

a)

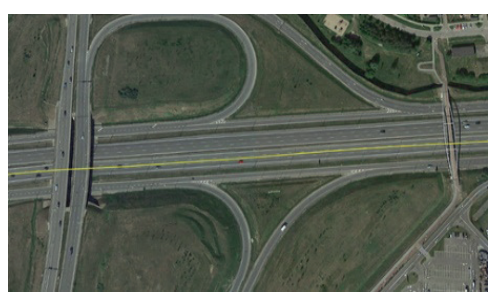

b)

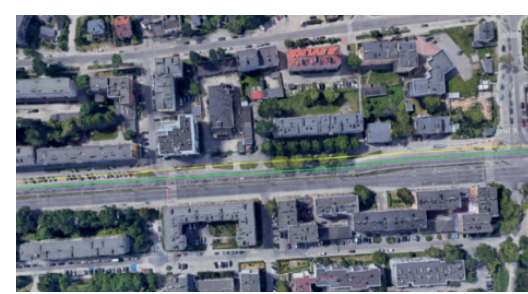

c)

Figure 4 Selected fragments of the visualization of the route Stara Kiszewa - Gdynia: the section of a winding road in Kolbudy (a); the section located on the Tricity ring road (b); the section located along Morska Street in Gdynia (c) (Poland) [44]

\subsection{Visualization of the route Glava - Arvika}

Taking into account that the recorded route is located at the latitude of $59{ }^{\circ} \mathrm{N}$ and GPS satellites operate in principle on orbit inclined to the equator by $55^{\circ}$ angle, the quality of the measurement may be much lower and burdened with a greater error. Additionally, anomalies caused by the speed drop to $0 \mathrm{~km} / \mathrm{h}$ while stopping at bus stops are visible along the entire length of the route (Figure $2 \mathrm{~b}$ ). Figure 5a shows clear jumps in position caused by the bus stopping and much smaller anomalies along the rest of the section. This situation is illustrated by the effect of the Kalman filter, which gives positive results for positioning in motion. The terrain conditions in this section are the best for the entire route. The road is surrounded by agricultural land and sparse surrounding trees. This is reflected in values of the HDOP coefficient, which is the lowest in the first minutes of the measurement and fluctuates slightly in the range from 0.8 to 1.6 (Figure $1 \mathrm{~b}$ ).

Figure 5b shows a fragment of the Glava - Arvika route in the forested area corresponding to the HDOP jumps, which falls in the period of UTC 5:33 - 5:38 shown in Figure 1b. The value of the coefficient fluctuates considerably and doubles from 3.2 to 6.4. The projection of the entire route section is inaccurate and is outside the road area. In extreme cases, the estimated error value, related to the road axis, is even $15 \mathrm{~m}$. This is due to the presence of tall trees close to the road, irregular course of the route and bus stops located in this area, causing the vehicle to stop.

The last landmark of the route is its final section in the city of Arvika (Figure 5c). It shows deviations of the recorded position from the road, caused by urban buildings obscuring the sky and increasing the risk of multipath errors. Figure $1 \mathrm{~b}$ shows that the value of the HDOP coefficient in the UTC period from 5:45:38 to 5:45:41 slightly increases from 2.4 to 3.2 . At the end of the route, when the bus enters the station area, the HDOP coefficient decreases to the minimum value for the entire route of 0.8 .

\subsection{Visualization of the Gdynia Centrum route}

The Gdynia Centrum route was covered on foot at a low speed of $1.24 \mathrm{~m} / \mathrm{s}$ on average (Figure 2c). In the section located on the Seaside Boulevard (Figure $6 a)$, slight deviations of the recorded route from the rectilinear route are visible. There were no sky obstacles near the receiver during the registration. Figure 1c shows that fluctuations in both the HDOP and the number of satellites occur much less frequently in relation to the measurement section located between the buildings on Polish Home Army street in Gdynia (Figure 6b).

The discussed section of the route was covered in the closest possible vicinity of high urban development. There are large anomalies in the determined horizontal positions along the entire length of the route. Taking into account that the pedestrian with the receiver was walking along the sidewalk on the right side of the road, it can be assumed that the positioning error at extreme moments was $15 \mathrm{~m}$. In Figure $1 \mathrm{c}$ the fluctuations of the HDOP are visible, which varies from 0.65 to 0.94 . During the period shown, the number of visible satellites ranged from 13 to 18, while the number of all the satellites varied from 33 to 37 (Figure 6c). This indicates that the dense buildings obscured $60 \%$ of the satellites visible to an observer in Gdynia during the measurement.

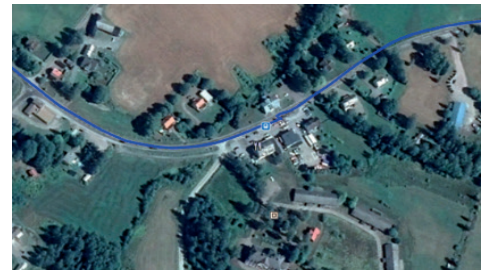

a)

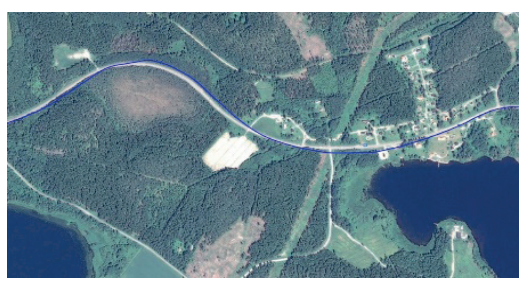

b)

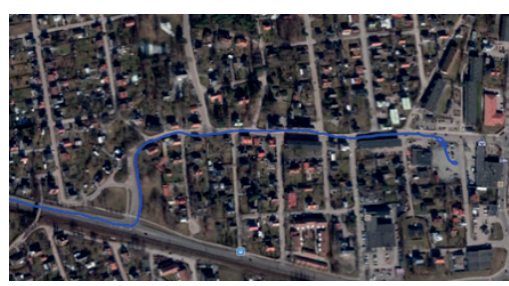

c)

Figure 5 Selected fragments of the visualization of the route Glava - Arvika: the section of road with bus stop (a); the section located in the forested area (b); the section in the city of Arvika (c) (Sweden) [44] 
a)
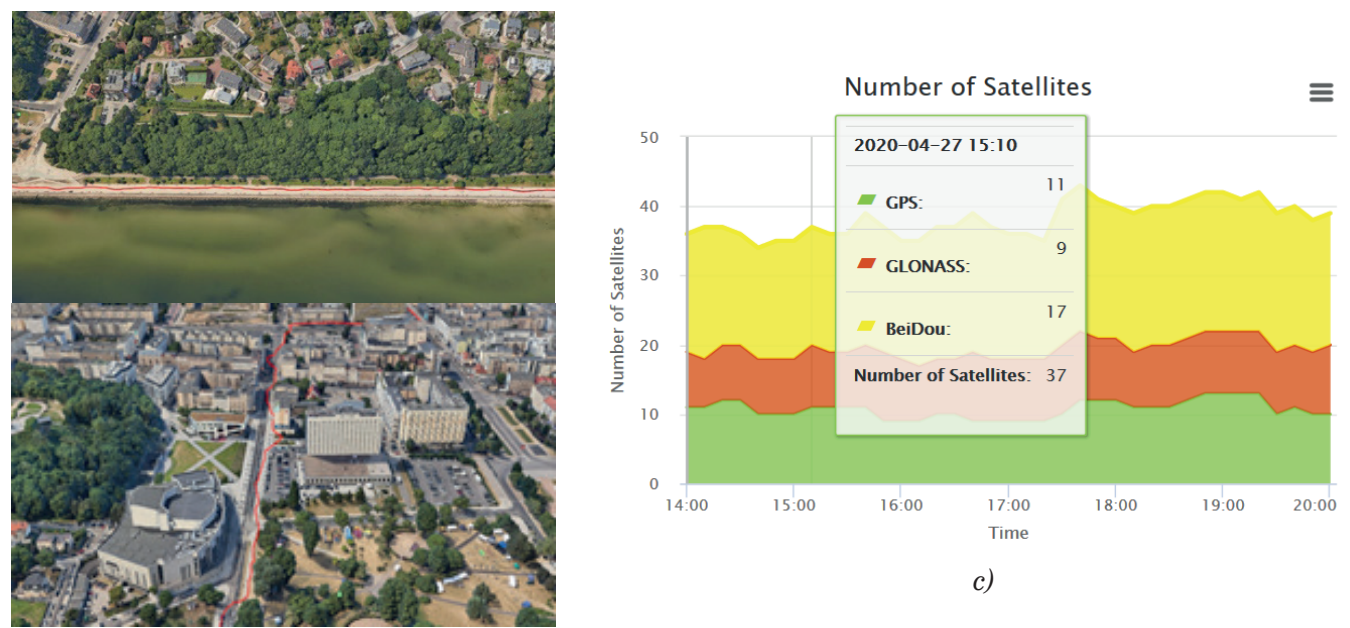

c)

Figure 6 Selected fragments of the route visualization Gdynia Centrum: the section located on the Seaside Boulevard (a); the section along Polish Home Army street in Gdynia (b) (Poland) [44] and the Trimble GNSS Planning Online window showing the number of available satellites (c) [46]

\subsection{Visualization of the Gdynia - Sopot route}

The last test route was recorded using a smartwatch in GPX format. For this reason, in contrast to the three previous routes, it was not possible to evaluate the parameters of the satellite constellation. The assessment of factors influencing the positioning accuracy was made based on the conditions of the presence of sky obstacles found in the field and speed. Figure 7a shows a section of the route located on one of the main public roads in Gdynia, where the car reached a higher speed than in the rest of the route (Figure 2d, UTC period 06:40:30 - 06:42:20). Moreover, there are no larger sky obstacles near the road, which makes the measurement conditions very favorable. The outliers that appear from time to time are eliminated by the Kalman filter, thanks to which a measurement error close to $1 \mathrm{~m}$ was obtained.

In the further part of the public road in question, the measurement conditions significantly different from the previous measurement conditions were noted, where there are many trees near the road, forming natural sky obstacles (Figure 7b). This results in a sixfold deterioration in the accuracy of the measurement in relation to the earlier part of the road. The projection of the track is located outside the edge of the road and deviates from the axis of the road lane on which the car was moving by approximately $6 \mathrm{~m}$.
The last section presented is a fragment of a public road in the neighboring city of Sopot (Poland). The route presented in Figure 7c is surrounded by high buildings causing disturbances in the rectilinear representation of the car route. The largest anomaly is located at the intersection of the roads and is associated with stopping of a vehicle and disruption of the Kalman filter (Figure $2 \mathrm{~d}$, UTC 06:51). The estimated error in the section shown was about $3 \mathrm{~m}$ at the extreme moment.

\section{Conclusions}

The paper presents the process of creating a visualization based on routes recorded by the mobile devices GNSS receivers. The NMEA and GPX formats require that saved positional data be processed and saved in KML format to be recognized by the Google Earth software. In addition to presenting the subsequent calculation steps, the study included the application of the presented procedure on results of the satellite measurements carried out on four routes located in Poland and Sweden. Measurements were made in various field conditions using three smartphones and one smartwatch. Apart from presenting the traveled routes, this article presents an analysis of the factors influencing the positioning accuracy. The dependence

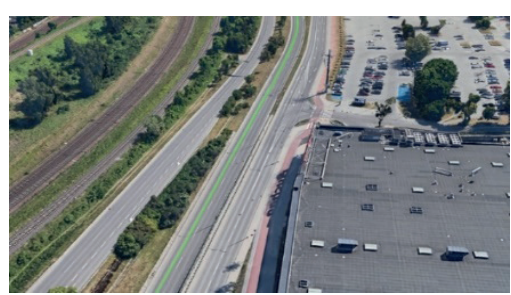

a)

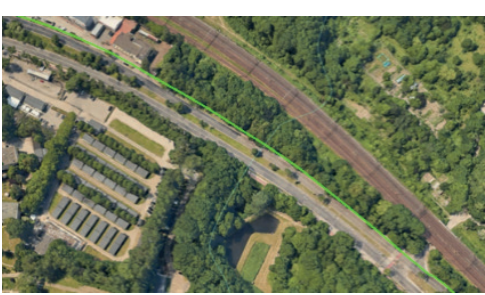

b)

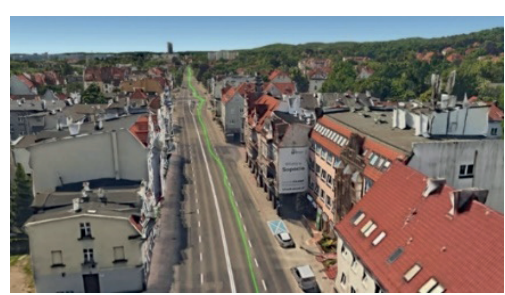

c)

Figure 7 Selected fragments of the visualization of the Gdynia - Sopot route (Poland): the section along Victory Avenue street street in Gdynia (section with favorable measurement conditions (a), wooded section (b)); the section along Polish Home Army street in Sopot (c) [44] 
of the quality of the obtained route mapping on the existing terrain barriers was noted on each of the routes. Depending on the size and distance of the shutters from the receiver, they increased the errors in the coordinates determined.

The study showed that with deterioration of the terrain conditions, the HDOP value increases and the number of satellites decreases, which is associated with a decrease in the accuracy of satellite positioning results. On the visualized measurement routes, it was also observed that with decrease in speed, the quality of the obtained mapping of the traveled route also decreased. This situation is due to the Kalman filter, which alters the current position coordinates with their previous values. This was especially noticeable in the places where the wheeled vehicles stopped and the route was covered on foot. Due to the different conditions of the measurements, it was not possible to precisely determine the average positioning accuracy of the devices used. The values of horizontal errors were approximated based on the route of roads and streets on the map and assuming the correctness of georeferencing of satellite images. Based on the research, the estimated values of the mean positioning errors were $15 \mathrm{~m}$ in difficult conditions and $1 \mathrm{~m}$ in favorable conditions.

The conducted study presented the process of creating a visualization of traveled routes based on the position data recorded in the NMEA and GPX formats. Additionally, the visualization of routes in the Google Earth software, thanks to the extensive function of adjusting the view, enables the basic accuracy analysis of the recorded position data. The NMEA format, thanks to the range of recorded data wider than the GPX format, enables the comparison of the constellation parameters of satellites without mapping in the basic graphical form of the route. Descriptive attributes in the form of the number of satellites and the HDOP are an important source of information about the accuracy of the measurements.

\section{References}

[1] WARD, N., SHAW, G., WILLIAMS, P., GRANT, A. The role of GNSS in e-navigation and the need for resilience. In: Proceedings of European Navigation Conference GNSS: proceedings [online]. 2010. Available from: https:/www.gla-rad.org/content/uploads/2018/01/the-role-of-gnss-in-e-navigation-and-the-need-for-resilience.pdf

[2] WEINTRIT, A. The electronic chart display and information system (ECDIS): an operational handbook. Boca Raton, USA: CRC Press, 2009. ISBN 9781439847640.

[3] WEINTRIT, A., NEUMANN, T. Safety of marine transport: marine navigation and safety of sea transportation. Boca Raton, USA: CRC Press, 2015. ISBN 9781138028593.

[4] MILLER, C. C. A beast in the field: the Google Maps mashup as GIS/2. Cartographica: The International Journal for Geographic Information and Geovisualization [online]. 2006, 41(3), p. 187-199 [accessed 2021-03-24]. ISSN 0317-7173. Available from: https://doi.org/10.3138/J0L0-5301-2262-N779

[5] WANG, M., LI, Q., HU, Q., ZHOU, M. Quality analysis of open street map data. The International Archives of the Photogrammetry, Remote Sensing and Spatial Information Sciences [online]. 2013, XL-2/W1, p. 155-158 [accessed 2021-03-24]. eISSN 2194-9034. Available from: https://doi.org/10.5194/isprsarchives-XL-2-W1-155-2013

[6] GORELICK, N., HANCHER, M., DIXON, M., ILYUSHCHENKO, S., THAU, D., MOORE, R. Google earth engine: planetary-scale geospatial analysis for everyone. Remote Sensing of Environment [online]. 2017, 202, p. 18-27 [accessed 2021-03-24]. ISSN 0034-4257. Available from: https://doi.org/10.1016/j.rse.2017.06.031

[7] VERMA, V., KUMAR, R., HSU, S. 3D building detection and modeling from aerial LIDAR data. In: 2006 IEEE Computer Society Conference on Computer Vision and Pattern Recognition CVPR'06: proceedings. Vol. 2. 2006. ISBN 0-7695-2597-0, p. 2213-2220.

[8] SPECHT, C., DABROWSKI, P., DUMALSKI, A., HEJBUDZKA, K. Modeling 3D objects for navigation purposes using laser scanning. TransNav: International Journal on Marine Navigation and Safety of Sea Transportation [online]. 2016, 10(2), p. 301-306 [accessed 2021-03-24]. ISSN 2083-6473. Available from: https://doi.org/10.12716/1001.10.02.12

[9] LOPEZ, A. J., SEMANJSKI, I., GAUTAMA, S., OCHOA, D. Assessment of smartphone positioning data quality in the scope of citizen science contributions. Mobile Information Systems [online]. 2017, 2017, 4043237 [accessed 2021-08-28]. ISSN 1875-905X. Available from: https://doi.org/10.1155/2017/4043237

[10] SPECHT, M., SPECHT, C., DABROWSKI, P., CZAPLEWSKI, K., SMOLAREK, L., LEWICKA, O. Road tests of the positioning accuracy of INS/GNSS systems based on MEMS technology for navigating railway vehicles. Energies [online]. 2020, 13(17), 4463 [accessed 2021-08-28]. ISSN 1996-1073. Available from: https://doi.org/10.3390/en13174463

[11] SPECHT, C., SZOT, T., DABROWSKI, P., SPECHT, M. Testing GNSS receiver accuracy in Samsung Galaxy series mobile phones at a sports stadium. Measurement Science and Technology [online]. 2020, 31(6), 064006 [accessed 2021-03-24]. ISSN 0957-0233. Available from: https://iopscience.iop.org/article/10.1088/1361-6501/ $\mathrm{ab} 75 \mathrm{~b} 2$ 
[12] SZOT, T., SPECHT, C., SPECHT, M., DABROWSKI, P. S. Comparative analysis of positioning accuracy of Samsung Galaxy smartphones in stationary measurements. PloS one [online]. 2019, 14(4), e0215562 [accessed 2021-03-24]. ISSN 1932-6203. Available from: https://doi.org/10.1371/journal.pone.0215562

[13] US DoD, 2020. Global Positioning System (GPS) Standard Positioning Service (SPS) Performance Standard 5th ed. [online] [accessed 2021-03-20]. Available from: https://www.gps.gov/technical/ps/2020-SPS-performancestandard.pdf

[14] NARKIEWICZ, J. GPS and other satellite systems / GPS $i$ inne systemy satelitarne (in Polish). Warsaw: WKiL, 2007. ISBN 9788320616422.

[15] SPECHT, C., SPECHT, M., DABROWSKI, P. Comparative analysis of active geodetic networks in Poland. In: International Multidisciplinary Scientific GeoConference SGEM: proceedings. 2017. ISBN 978-619-7408-02-7, p. 163-176.

[16] MUSULIN, I., BRCIC, D., KOS, S. A research study of handheld multiconstellation GNSS receivers satellite positioning performance. In: Annual Baska GNSS Conference: proceedings. 2015. ISSN 1849-7306. p. 63-84.

[17] SPECHT, C., DABROWSKI, P. S., PAWELSKI, J., SPECHT, M., SZOT, T. Comparative analysis of positioning accuracy of GNSS receivers of Samsung Galaxy smartphones in marine dynamic measurements. Advances in Space Research [online]. 2019, 63(9), p. 3018-3028 [accessed 2021-08-28]. ISSN 0273-1177. Available from: https://doi.org/10.1016/j.asr.2018.05.019

[18] TANG, L., YING, S., LI, L., BILJECKI, F., ZHU, H., ZHU, Y., YANG, F., SU, F. An application-driven LOD modeling paradigm for 3D building models. ISPRS Journal of Photogrammetry and Remote Sensing [online]. 2020, 161, p. 194-207 [accessed 2021-03-24]. ISSN 0924-2716. Available from: https://doi.org/10.1016/j. isprsjprs.2020.01.019

[19] BURDZIAKOWSKI, P., SPECHT, C., DABROWSKI, P. S., SPECHT, M., LEWICKA, O., MAKAR, A. Using UAV photogrammetry to analyze changes in the coastal zone based on the Sopot tombolo (Salient) measurement project. Sensors [online]. 2020, 20(14), 4000 [accessed 2021-03-24]. ISSN 1424-8220. Available from: https://doi.org/10.3390/s20144000

[20] SPECHT, C., LEWICKA, O., SPECHT, M., DABROWSKI, P., BURDZIAKOWSKI, P. Methodology for carrying out measurements of the tombolo geomorphic landform using unmanned aerial and surface vehicles near Sopot pier, Poland. Journal of Marine Science and Engineering [online]. 2020, 8(6), 384 [accessed 2021-03-24]. ISSN 2077-1312. Available from: https://doi.org/10.3390/jmse8060384

[21] DABROWSKI, P., SPECHT, C., SPECHT, M., BURDZIAKOWSKI, P., MAKAR, A., LEWICKA, O. Integration of multi-source geospatial data from GNSS Receivers, Terrestrial Laser Scanners and Unmanned Aerial Vehicles. Canadian Journal of Remote Sensing [online]. Paper accepted for publication. ISSN 0703-8992. Available from: https://doi.org/10.1080/07038992.2021.1922879

[22] MACIUK, K. The applications of GNSS systems in logistics. Budownictwo i Architektura [online]. 2018, 17(3), p. 181-188 [accessed 2021-03-24]. ISSN 1899-0665. Available from: https://doi.org/10.24358/Bud-Arch_18_173_13

[23] ASTARITA, V., FESTA, D. C., GIOFRE, V. P. Mobile systems applied to traffic management and safety: a state of the art. Procedia Computer Science [online]. 2018, 134, p. 407-414 [accessed 2021-03-24]. ISSN 1877-0509. Available from: https://doi.org/10.1016/j.procs.2018.07.191

[24] STOCKX, T., HECHT, B., SCHONING, J. Subway PS: towards smartphone positioning in underground public transportation systems. In: 22nd International Conference on Advances in Geographic Information Systems ACM SIGSPATIAL 2014: proceedings. 2014. ISBN 978-1-4503-3131-9, p. 93-102.

[25] REHRL, K., GOLL, N., LEITINGER, S., BRUNTSCH, S. Combined indoor/outdoor Smartphone navigation for public transport travelers [online]. 2005. Available from: people.cs.clemson.edu/ johnmc/courses/cpsc875/ projects/rehrl2.pdf

[26] JOUBERT, N., REID, T. G., NOBLE, F. Developments in modern GNSS and its impact on autonomous vehicle architectures. In: 2020 IEEE Intelligent Vehicles Symposium: proceedings. IEEE. 2020. ISBN 9781728166742 , p. 2029-2036.

[27] BUJAK, A., TOPOLSKA, K. Increasing the efficiency of the transport process by eliminating weak points in enterprise management process transport. Logistyka [online]. 2014, 6, p. 4-5 [accessed 2020-05-03]. ISSN 12315478. Available from: http://yadda.icm.edu.pl/yadda/element/bwmeta1.element.baztech-18e9add6-e2f8-4e42b755-5707891105d0

[28] NMEA [online] [accessed 2020-04-10]. Available from: https://www.nmea.org

[29] BETKE, K. The NMEA 0183 protocol [online]. 2001. Available from: https://tronico.fi/OH6NT/docs/NMEA0183. pdf

[30] NMEA 0183 - Standard for interfacing marine electronic devices - NMEA [online] [accessed 2020-04-10]. 2002. Available from: http://www.plaisance-pratique.com/IMG/pdf/NMEA0183-2.pdf

[31] NOLAN, D., LANG, D. T. XML and web technologies for data sciences with R. New York: Springer, 2014. ISBN 9781461478997. 
[32] GPX [online] [accessed 2020-05-19]. Available from: https://www.topografix.com/gpx_resources.asp

[33] HOLDENER, A. T. HTML5 geolocation. USA: O'Reilly Media, Inc., 2011, ISBN 9781449304720.

[34] OGC [online] [accessed 2020-04-17]. Available from: https://www.ogc.org/standards/kml

[35] KUMAR, M. World geodetic system 1984: a modern and accurate global reference frame. Marine Geodesy [online]. 1988, 12(2), p. 117-126 [accessed 2021-03-24]. ISSN 0149-0419. Available from: https://doi.org/10.1080/15210608809379580

[36] LEMOINE, F. G., FACTOR, J. K., KENYON, S. C. The development of the joint NASA GSFC and the National Imagery and Mapping Agency (NIMA) geopotential model EGM96 (Vol. 206861) [online] [accessed 2021-03-24]. Greenbelt, Maryland, USA: National Aeronautics and Space Administration, Goddard Space Flight Center, 1998. p. 490-539. Available from: https://science.gsfc.nasa.gov/sed/content/uploadFiles/publication_files/EGM96_ NASA-TP-1998-206861.pdf

[37] KML Reference - Google [online] [accessed 2020-09-19]. Available from: https://developers.google.com/kml/ documentation/kmlreference

[38] Samsung A30S - Samsung [online] [accessed 2020-08-25]. Available from: https://www.samsung.com/pl/ smartphones/galaxy-a30s/SM-A307FZGVXEO/

[39] iPhone 7 - Apple [online] [accessed 2020-08-25]. Available from: https://web.archive.org/web/20160914204242/ https://www.apple.com/pl/iphone-7/

[40] Huawei Mate 10 Lite - Huawei [online] [accessed 2020-08-25]. Available from: https://consumer.huawei.com/pl/ support/phones/mate10-lite/

[41] Samsung Gear S3 Frontier - Samsung [online] [accessed 2020-06-03]. Available from: https://www.samsung.com/ us/mobile/wearables/smartwatches/samsung-gear-s3-frontier-sm-r760ndaaxar/

[42] Google Maps [online] [accessed 2020-03-19]. Available from: https://www.google.com/maps

[43] SPECHT, C. System GPS. Pelplin: Bernardinum Sp. z o.o., 2007. ISBN 9788373804692.

[44] Google Earth [online] [accessed 2020-09-19]. Available from: https://www.google.com/intl/pl/earth/

[45] KALMAN, R. E. A new approach to linear filtering and prediction problems. Journal of Basic Engineering [online]. 1960, 82(Series D)] p. 35-45 [accessed 2021-03-24]. ISSN 0021-9223. Available from: https://doi.org/10.1115/1.3662552

[46] Trimble GNSS planning [online] [accessed 2020-09-19]. Available from: https://www.gnssplanning.com/\#/settings 